\title{
Inspection Case and Its Failure Cause Analysis of Leaked Storage Tank
}

\author{
Xing Shu ${ }^{a}$, Fang Zhou ${ }^{b}$, Shen Gongtian ${ }^{c}$, Li Guanghai ${ }^{d}$, Zhao Yanxiu ${ }^{\mathrm{e}}$ \\ Hazardous Chemical Substance Equipment Division, China Special Equipment Inspection and \\ Research Institute, Beijing, P. R. China \\ aemail: allancraft@163.com, bemail: fangzhou@csei.org.cn, ${ }^{\mathrm{c} e}$-mail:

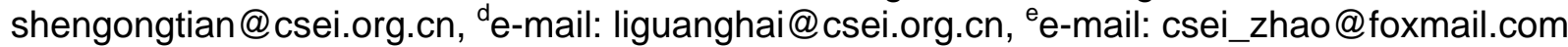

Keywords: atmospheric storage tank; failure; leakage; magnetic flux leakage testing.

\begin{abstract}
Leakage is a frequently occurred failure mode during the operation of atmospheric storage tanks with large probability of occurrence. According to different design and operation conditions, there are various different causes for the leakage of storage tank. The inspection of a storage tank of certain chemical enterprise before and after leakage is discussed in this paper. Before, the change in operation condition during this period is also introduced and the leakage cause of the storage tank is analyzed. The analysis result shows that related suggestions for leakage inspection of storage tank and preventing leakage accidents to provide guidance for the safe operation of atmospheric storage tank.
\end{abstract}

\section{Introduction}

Atmospheric storage tank, widely applied into many fields such as industrial production and traffic and transportation, plays a key role in production and transportation. Large metal storage tank has features such as large volume, inflammable, explosive and poisonous stored medium. Once in case of the occurrence of leakage or explosion accidents, the disastrous consequence will be usually caused and the environmental pollution will be aggravated. Thus, huge loss and damages could be brought to the social economy, production and people's life and properties. Through comparison of operation condition of one leaked storage tank of certain chemical enterprise and change in medium into the inspection result before and after leakage, the correlation between process change and failure of storage tank is discussed and the causes for leakage are analyzed in this paper. As a result, related suggestions for future operation, inspection and safe protection of the storage tank are proposed.

\section{Main Technical Parameters}

Main technical parameters of the storage tank are as below shown in the table 1 . The storage tank was put into use in Jun., 2010, in which the stored medium is heavy oil, mainly providing transit shipment and storage for ancillary equipment. According to the technology of upstream device, the medium contains alkaline and acidic substances sometimes. The medium composition of its material was quite complicated and its temperature was high. Besides heat preservation was designed for storage tank wall board, the tank was also equipped with a heat exchanger to control its operation temperature.

\section{Inspection History, Operation Condition and Process Change}

Due to the complicated, high-temperature and corrosive composition of the medium stored in the storage tank, the material thickness of the tank was thicker than that of storage tank of the same specification. Besides, thick epoxy coal pitch was used on the baseboard of the tank for corrosion prevention.

Through four years' usage, the tank was opened for the first time to perform overall inspection in May, 2014. The inspection items mainly include macroscopic thickness measuring, baseboard leakage flux scanning, circumferential weld between the first and second wall board, magnetic particle testing of longitudinal seam of the first laminate and large fillet weld. Through detection and 
inspection, no abnormal conditions were found. When performing in-tank inspection, there was partial residue on inner wall and baseboard inside tank not cleaned up, its surface erosion resistant coating was not damaged. Besides, the corrosion of the base material is not found. Through eddy current testing of heat exchange tube for the storage tank, there was no abnormality found. The above test proved that it can be used continuously under existing operation and process condition.

Table 1 Main technical parameters of the storage tank

\begin{tabular}{|c|c|c|c|}
\hline Type of storage tank & Vertical cylinder type & Tank top type & Arch apex \\
\hline Design specification & $\begin{array}{l}\text { API 620-2007 "large } \\
\text { low-voltage welded } \\
\text { storage tank design and } \\
\text { building” }\end{array}$ & Nominal volume & $538 \mathrm{~m}^{3}$ \\
\hline Design pressure & $-600 \mathrm{~Pa} \sim 14000 \mathrm{~Pa}$ & Design temperature & $130{ }^{\circ} \mathrm{C}$ \\
\hline Operation pressure & $8000 \mathrm{~Pa}$ & Operating temperature & $95 / 85^{\circ} \mathrm{C}$ \\
\hline Main material & Q235-B & Operation medium & Heavy oil \\
\hline Nominal thickness & $\begin{array}{l}\text { Shell: } 10 / 10 / 10 / 8 / 8 / 8 \mathrm{~mm} \\
\text { Bottom: } 12 \mathrm{~mm} \\
\text { Roof: } 8 \mathrm{~mm}\end{array}$ & Corrosion allowance & $3 \mathrm{~mm}$ \\
\hline Inner diameter & $8000 \mathrm{~mm}$ & Tank wall height & $10700 \mathrm{~mm}$ \\
\hline Heat preservation & Tank wall: rock wool & In-tank anti-corrosion & $\begin{array}{l}\text { Tank bottom: } \\
\text { epoxy coal pitch }\end{array}$ \\
\hline Weld joint coefficient & 0.85 & Date of putting into use & 2010.6 \\
\hline
\end{tabular}

Afterwards, due to the process adjustment, the base oil of another storage tank was transported to the tank in Aug., 2014. It's found that the heat exchange tube bundle of the storage tank was leaked in Sep., 2014, but it was put into use again after replacement. Due to insufficient thermal load of heat exchanger, the upstream process device process was changed and the oil was input into the tank again in Dec., 2015. Until Aug., 2016, the device was overhauled and normal process was restored. However, the leakage occurred in Sep., 2016. The field situation is as shown in the Fig. 1.

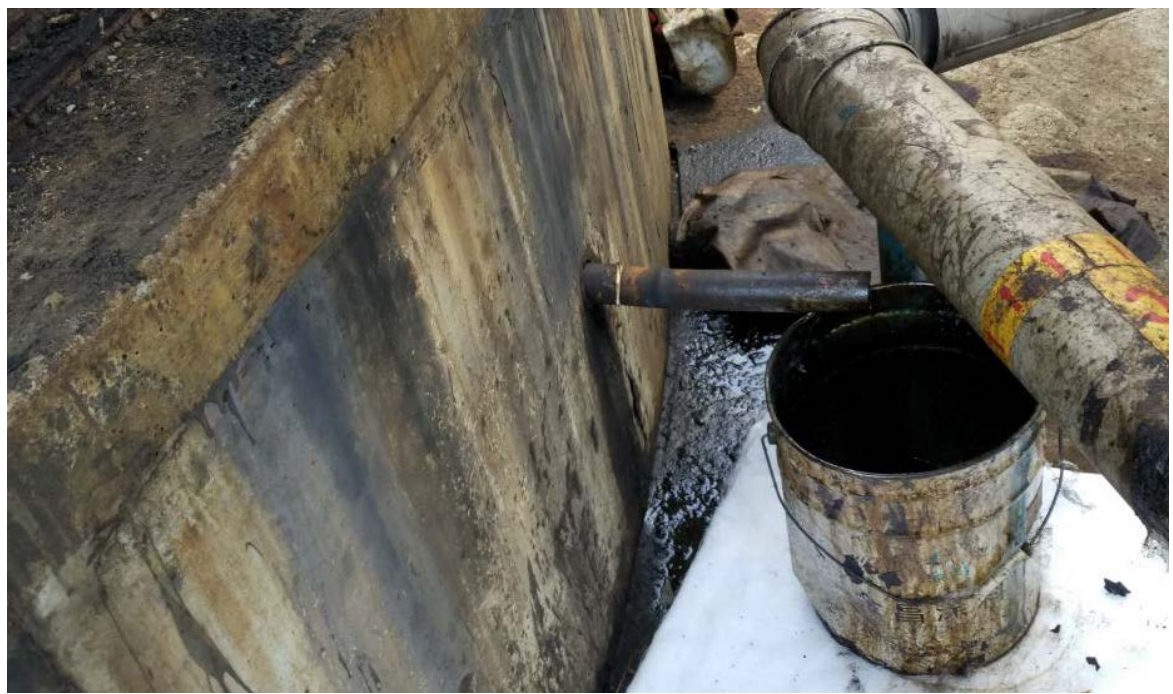

Fig. 1 Leakage scene of the storage tank

Organization of the Text As described by the device manager, the leakage of the storage tank was the oil leakage of the leakage detection hole in foundation at all directions. Due to the high oil liquid level stored at that time, it's too late to unload the oil. Thus, there were enormous leaked substances deposited on the foundation. Afterwards, the oil was leaked outwards from between the baseboard and foundation of the storage tank. 


\section{Formulation and Implementation of Inspection Scheme for Leaked Storage Tank}

Preliminary Analysis of Leak Point. Through preliminary review on the field, it' found that there was no any leakage trace on the wallboard of the storage tank. Therefore, it was preliminarily judged that the leak points were mainly on the baseboard area of the storage tank. The following preliminary judgment on the leak point and failure location was made.

Large Fillet Weld. This area was where the stress of the vertical cylinder type was the most complicated. Besides, compared into the one of the same specification, the tank was higher and the fluctuation of liquid level was frequent. The area suffers from irregular load change. The fatigue damage could be easily caused to the welded joint and nearby heat affected zone and even base material

Butt Weld of Baseboard. Butt welding was adopted for the baseboard of the tank, as shown in the Fig. 2. Through this welding method, the baseboard was firstly welded to a piece of cushion board through spot welding and then to another piece through butt welding. However, the welding stress might be caused through two times' welding. Thus, stress concentration would be caused to the last welded joint and the failure would be caused.

Base Material of the Baseboard. Due to the change in operation condition and process adjustment, the composition of medium stored in the tank was different from that previously. Thus, the anti-corrosion coating fell off and the base material of the baseboard was eventually corroded and the leakage was caused.

Drainage Channel. Drainage channel of the storage tank was at the lowest point according to the terrain of the whole tank. In this way, the heavy components of the medium mainly the water can get together here and was discharged out of the tank through the pipe connected to the drainage channel.

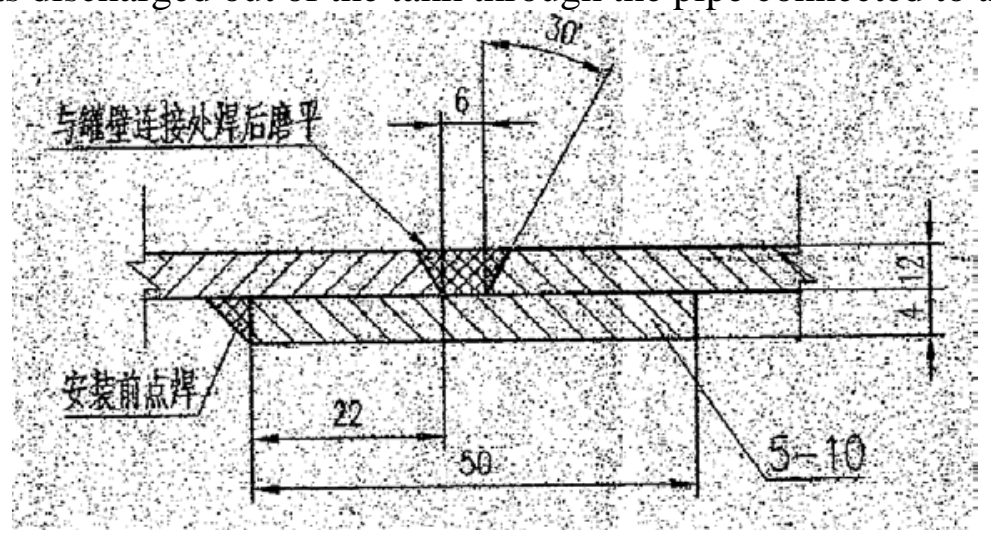

Fig. 2 Baseboard welding manner of the storage tank

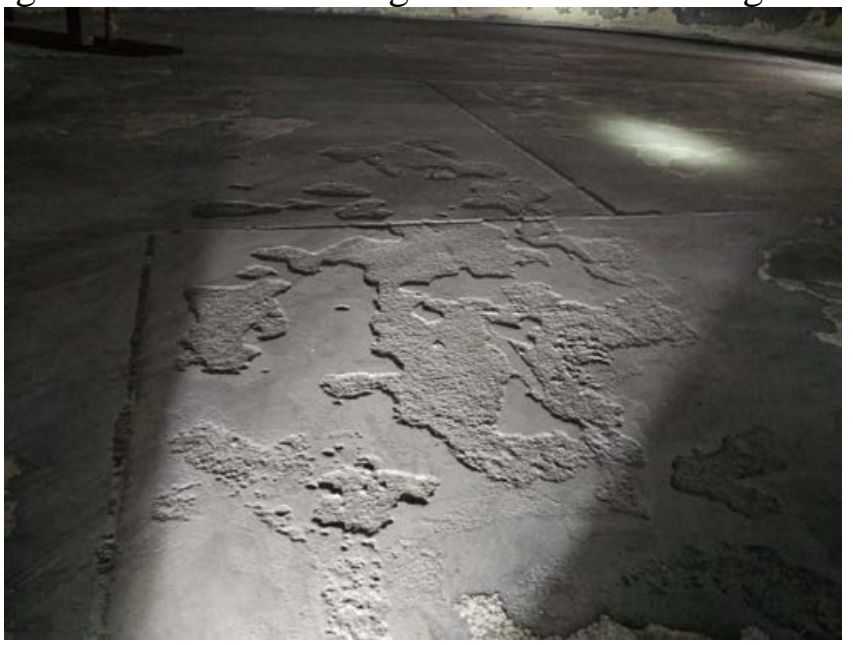

Fig. 3 Corrosion of baseboard of the storage tank

Formulation and Implementation of Inspection Scheme. According to the preliminary analysis of the leak point location, the bottom of the tank was mainly detected and tested. The specific inspection items were described as below: 
(1)Comprehensive and macroscopic inspection of the inside of the storage tank;

(2)Magnetic flux leakage testing and thickness measuring inspection of the whole baseboard;

(3)Fluorescent magnetic powder inspection of large fillet weld of the baseboard;

(4)Super vacuum leak test of the base material of the baseboard and weld;

In late Sep., 2016, the tank was cleared and internal sand blasting of the tank was conducted according to the inspection requirement, which met test conditions. Firstly, macroscopic inspection was performed. Due to the thick anti-corrosion layer inside the tank, the sand was not completely removed. However, it's found that there was large area of partial corrosion on the surface of naked bottom of the tank, as shown in the Fig. 3.

Through thickness measuring spot check, it's found that the corrosion part was reduced by 3-4mm. Besides, the butt weld was severely corroded. The deepest part was $4 \mathrm{~mm}$, as shown in the Fig. 4.

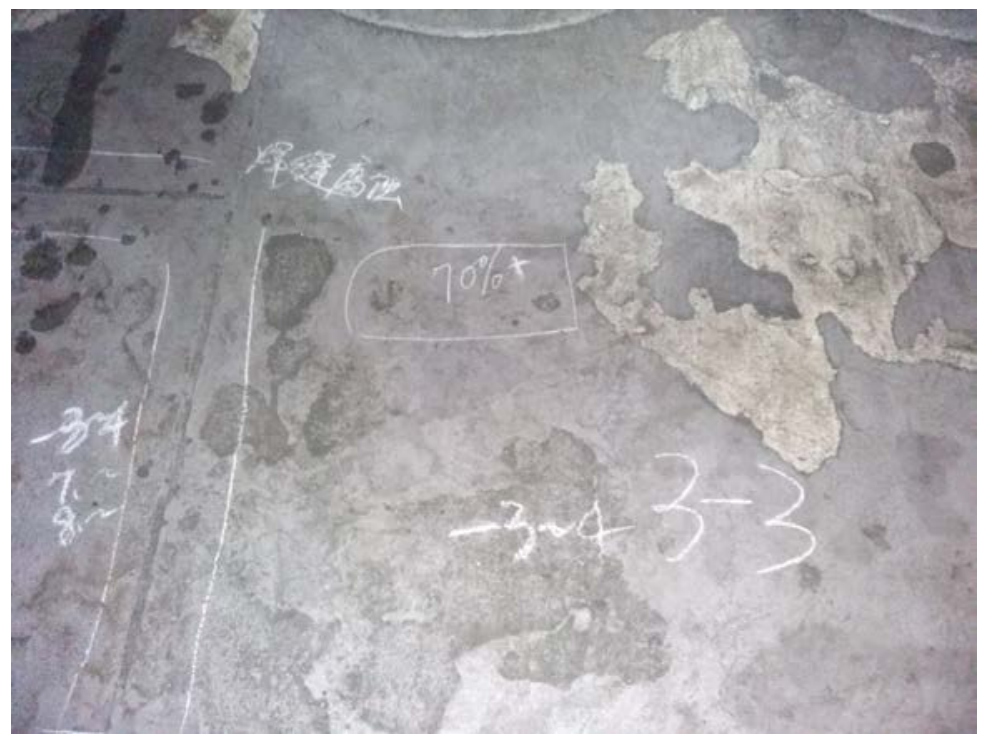

Fig. 4 Corrosion depth of baseboard of the storage tank

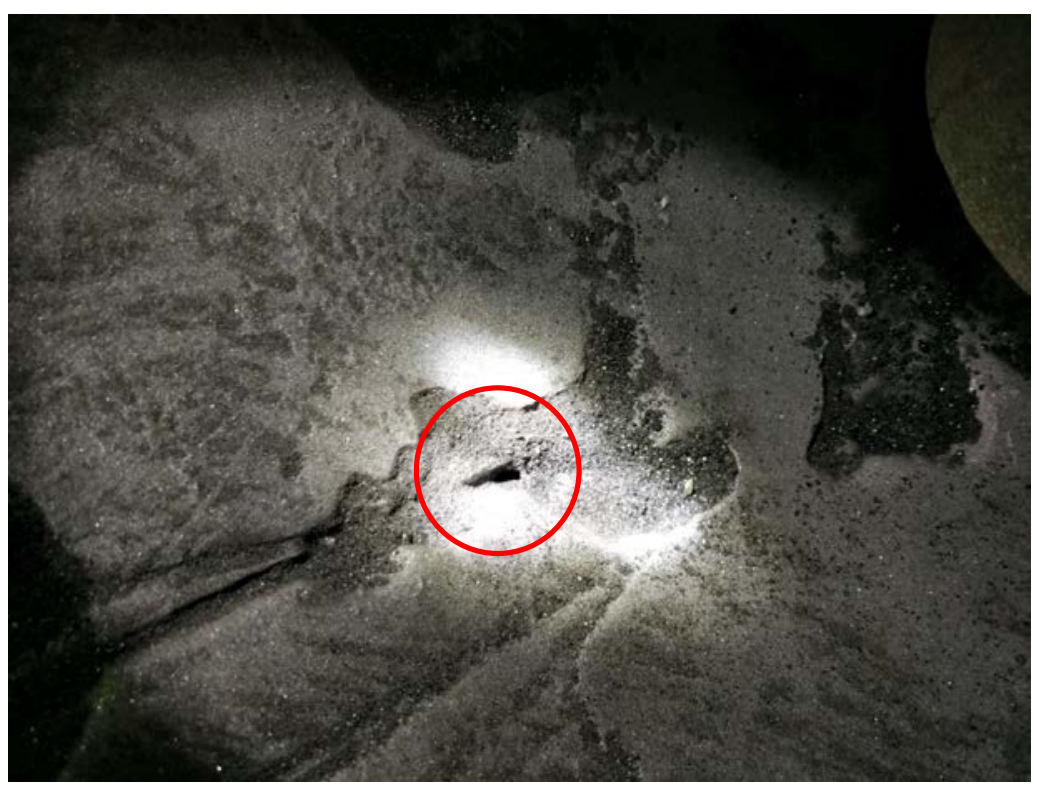

Fig. 5 Corrosion perforation of drainage channel

Through macroscopic inspection of drainage channel, it's found that the partial corrosion was serious and there was one leak point, whose dimension was about $30 \times 10 \mathrm{~mm}$, as shown in the Fig. 5 .

Through macroscopic inspection, it's not found that there was any leakage trace and corrosion damage on large fillet weld. It had been judged that the leak point of the storage tank was perforation of drainage channel and the possibility of large fillet weld leakage was eliminated. To further confirm the corrosion of base material of the baseboard, it's still necessary to conduct magnetic flux leakage test. The result of magnetic flux leakage test was as shown in the Fig. 6 and Fig. 7. 


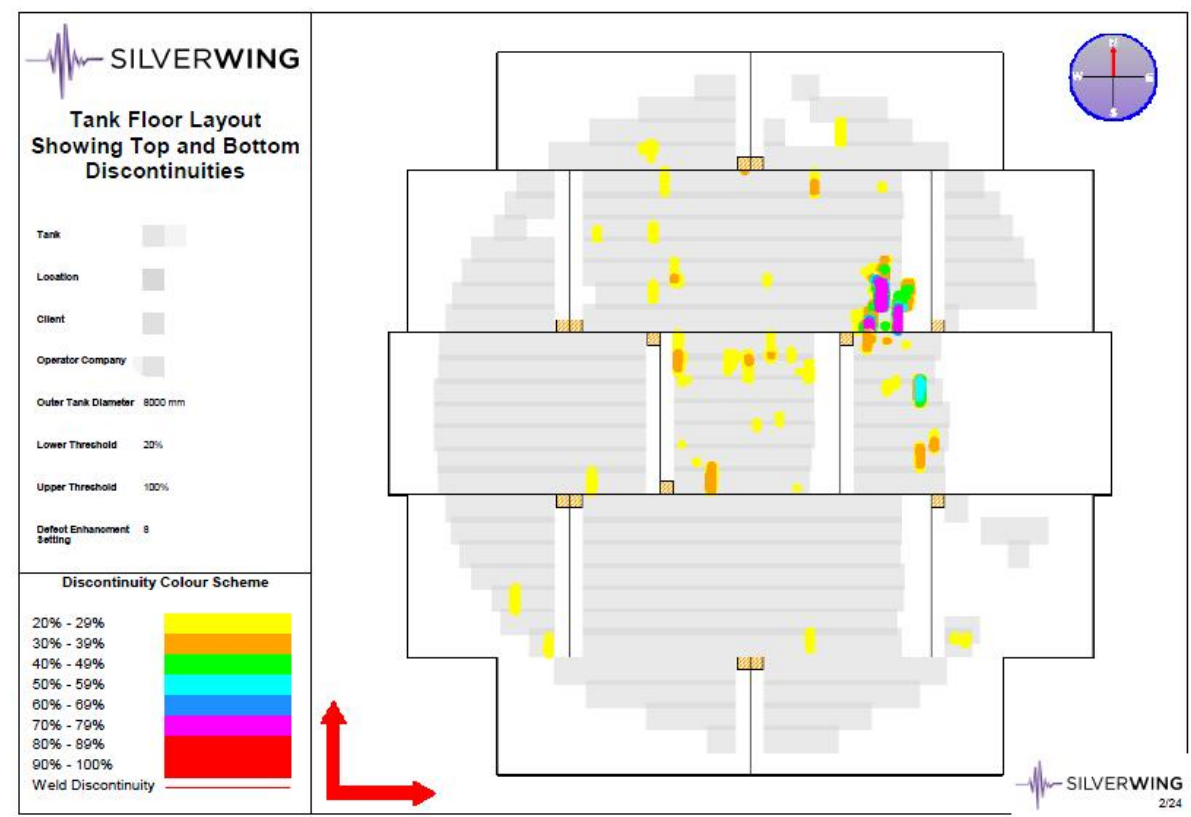

Fig. 6 Magnetic flux leakage scanning result of the baseboard and equivalent depth of corrosion

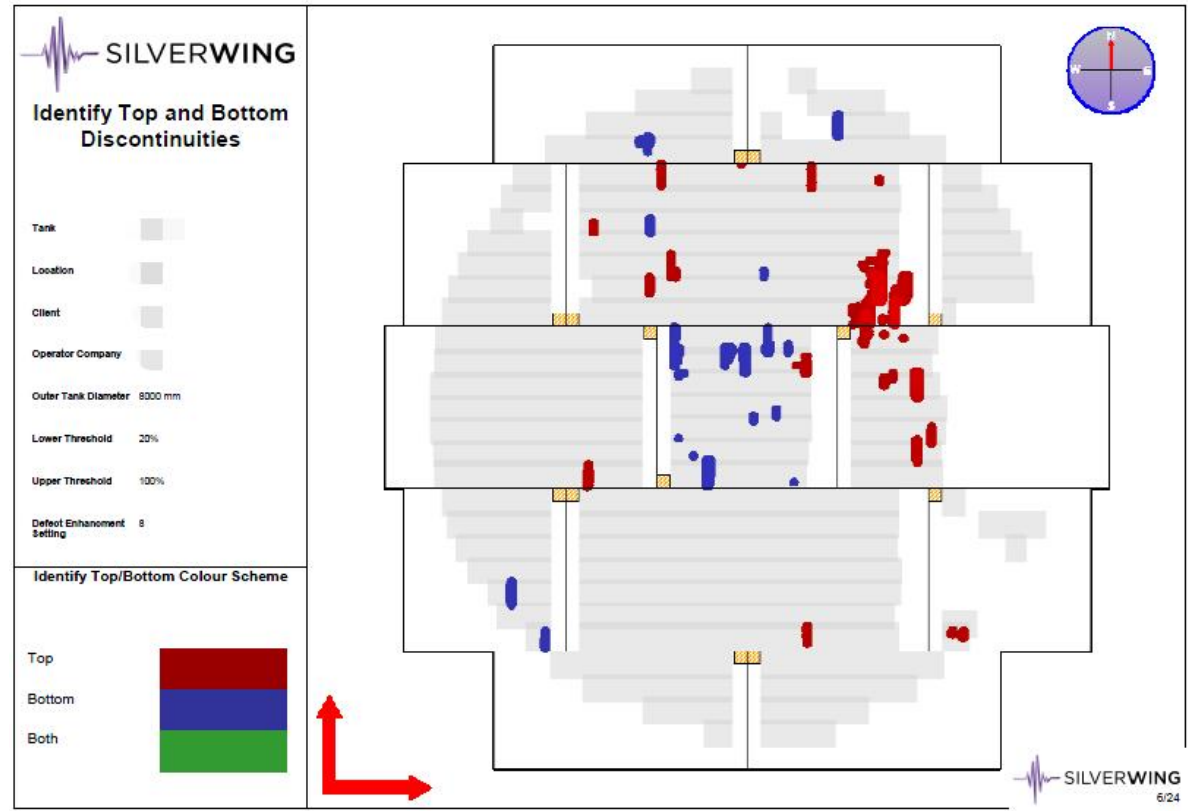

Fig. 7 Magnetic flux leakage scanning result of the baseboard and upper and lower surface

According to the magnetic flux scanning result, it revealed that the equivalent corrosion depth reached $70 \%$ and there was corrosion on the upper and lower surface to a varying degree and the corrosion on the terrain of the storage tank was more serious.

\section{Leakage Cause Analysis}

After the leak point was determined through inspection and through discussion with the equipment manager of the user and research analysis, the causes for the leakage of the storage tank were judged as below.

(1)Due to the change in operation condition and process, the acid-base balance inside the storage tank was destroyed;

(2)The corrosive medium was deposited on the bottom of the storage tank and collected on the lower position of the storage tank;

(3)Due to the high operation temperature, the corrosion was expedited and the corrosion of heat exchange tube bundle, drainage channel and base material and weld joint of the baseboard was caused successively. 


\section{Conclusions}

The material was selected for the wall thickness of the storage tank conservatively at the beginning of the design of the storage tank and anti-corrosion coating with excellent performance was used. However, through the first time's inspection result, it could be found that the tank could meet safety operation under normal working condition, but the corrosion and leakage was caused to the tank for two times within short time after the process adjustment and change in operation condition. It indicated that the change in service environment of the storage tank could easily cause the damage to the storage tank. Therefore, the control of operation condition should be strengthened in daily use and maintenance of the storage tank. It should be evaluated before process adjustment and run under monitoring condition after adjusted to ensure the use safety.

\section{Acknowledgment}

This work was supported in part by the financial from National key scientific instrument and equipment development project (Project No.2012YQ090175), the Science and technology projects of General administration of quality supervision, inspection and quarantine of P. R. China (AQSIQ), (Project No.2013QK018), (Project No.2014QK244), Quality inspection of public welfare scientific research Foundation of China (Project No.201310156), and PhDs Foundation (Project No.2016 nei21).

\section{References}

[1] FANG Z, JIA G D, LIU D Y. Study On Carburizing Inspection Of Cracking Furnace Tube Using Acoustic Emission Technique [C]. Proceedings of the ASME 2014 Pressure Vessels \& Piping Conference, 2014.

[2] FANG Z, CHEN Z. P, WANG L. Study on high-temperature naphthenic acid corrosion of type 304 and type 316L stainless steel and their welded joints[C]. ASME Meeting. 5 (2009) 351-357.

[3] FANG Z, WEIWEI H, DEYU L. Study on Metallography Test of the Steel SPV490 for Atmospheric Storage Tank after Fire[C]. Proceedings of the ASME 2016 Pressure Vessels \& Piping Conference. 2016.

[4] FANG Z, CHEN Z. P, JIA G D. Dynamic Experimental Investigation on the Self-Vibration Characteristics of Liquid Storage Tanks Under Seismic Excitations[C]. 2013 ASME Pressure Vessels and Piping Division Conference, July 14-18, Paris, France. ASME Pressure Vessels Piping, 2013.

[5] FANG Z, CHEN Z P, YAN S J, et al. Ф $2800 \mathrm{~mm}$ nonmetal storage tank is a large earthquake simulation test of anchorage in Chinese[J]. Pressure Vessels. 2012, 29(6): 1-8.

[6] ZHAO Y X. Nondestructive Testing Technology in the Application of Active Steel Vertical Welding Atmospheric Storage Tank Inspection [J]. Nondestructive Testing. 2014, 36(8): 81-84

[7] GU L W. The Damage Mechanism and Repairation of Atmospheric Storage Tank [J]. Chemical Enterprise Management. 2013(6):5-6.

[8] XU ZQ, WANG G J. Corrosion Cause of Atmospheric Tank and its Protection[J]. Petrochemical Safety and Environmental Protection Technology. 2003(3):40-42.

[9] YAN H, SHEN G T, LI B X, ZHANG Y L. Magnetic Flux Leakage Detection of Corrosion in Atmospheric Storage Tank Floor and its Failure Analysis[J]. Nondestructive Testing, 2006, 28(2):75-77.

[10] WANG X, LIU F, LU Y. Magnetic Flux Leakage Detection and Corrosion Failure Analysis of the Bottom Plate of Atmosphere Storage Tank [J]. Contemporary Chemical Industry. 2015(11):2703-2705. 